\title{
SEGURANÇA COM BRINQUEDOS DE PARQUES INFANTIS: UMA INTRODUÇÃO AO PROBLEMA
}

Harada MJCS, Pedreira MLG, Andreotti JT. Segurança com brinquedos de parques infantis: uma introdução ao problema. Rev Latino-am Enfermagem 2003 maio-junho; 11(3):383-6.

A finalidade deste estudo é abordar temática pouco explorada na literatura nacional relativa à prevenção de acidentes relacionados ao uso de brinquedos de parques infantis. Nos Estados Unidos da América, estima-se que, anualmente, ocorrem mais de 200.000 acidentes com crianças, em parques infantis. Além de discutir esse problema, apresentamos algumas recomendações gerais sobre segurança nesses locais e a reflexão da necessidade de alertar e educar a sociedade sobre a importância da prevenção.

DESCRITORES: segurança, prevenção de acidentes, enfermagem pediátrica

\section{PLAYGROUND SAFETY: AN INTRODUCTION TO THE PROBLEM}

This study aims to approach the theme of accident prevention in relation to the use of playground toys, which is little explored in national literature. It is estimated that, annually, more than 200,000 accidents with children happen in playgrounds in the United States of America. Besides discussing this problem, we present some general recommendations about safety in these places and a reflection on the need to alert and educate society about the importance of prevention.

\section{SEGURIDAD CON JUEGOS DE PARQUES INFANTILES: UNA INTRODUCCIÓN AL PROBLEMA}

El objetivo de este estudio es abordar un tema poco explotado en la literatura nacional acerca de la prevención de accidentes relacionados con el uso de juegos en parques infantiles. En los Estados Unidos de Norte América se estima que anualmente ocurren más de 200.000 accidentes con niños en parques infantiles. Además de discutir este problema, presentamos algunas recomendaciones generales sobre la seguridad en estos locales y la necesidad de alertar y educar a la sociedad sobre la importancia de la prevención.

DESCRIPTORES: seguridad, prevención de accidentes, enfermería pediátrica

\footnotetext{
${ }^{1}$ Enfermeira, Professor do Departamento de Enfermagem da Disciplina de Enfermagem Pediátrica, Doutoranda em Enfermagem, e-mail: jjharada@uol.com.br; ${ }^{2}$ Enfermeira, Doutora em Enfermagem Pediátrica; ${ }^{3}$ Aluna do $4^{\circ}$ ano de Graduação em Enfermagem. Universidade Federal de São Paulo
} 
INTRODUÇÃO

Os acidentes na infância são a principal causa de mortalidade e morbidade em crianças menores de 18 anos. $O$ alto índice de mortes prematuras e seqüelas é acompanhado de elevado custo econômico, sendo estimado que a perda em geração de produtividade é maior do que a ocasionada pelo câncer e doenças cardíacas. Entretanto, apesar de estatísticas fornecidas pela comunidade científica e da divulgação em veículos de comunicação como TV, rádio, jornais e revistas, ao se analisar esse problema sob o prisma da prevenção, observase pouca valorização, quando se considera o grave problema social que acarreta ${ }^{(1)}$.

Os acidentes na infância envolvem vários segmentos populacionais, com peculiaridades marcantes em relação à faixa etária, local de ocorrências e características ou circunstâncias em que se desenvolvem. Nesse contexto, os parques infantis e seus brinquedos podem representar um perigo para as crianças quando não se encontram adequadamente estruturados, sendo esse problema freqüentemente ignorado pelos responsáveis. Todavia, observa-se que, na maioria das vezes, esses eventos poderiam ser evitados com medidas simples de prevenção.

Em nosso país, existem normas de segurança para brinquedos de parques infantis, estabelecidas pela Associação Brasileira de Normas Técnicas ${ }^{(2)}$. Porém, observa-se, na prática, que essas normas são pouco respeitadas ou até mesmo desconhecidas pela comunidade, sendo que a falta de estudos epidemiológicos sobre o tema, inviabiliza uma mudança de conduta, respaldada por um retrato mais fidedigno das ocorrências comumente observadas.

Em uma pesquisa realizada em 1999, no País de Gales, alguns parques infantis, previamente selecionados, foram observados durante 18 meses, a fim de se verificar a incidência dos acidentes ocorridos com crianças nesses locais. Posteriormente, implantaram-se algumas medidas simples de segurança como a instalação de superfícies de borracha sob e ao redor dos equipamentos. Após as intervenções, obteve-se a redução de, aproximadamente, 2,5 vezes no número de acidentes nos parques onde houve alterações, comprovando-se que as estratégias implementadas foram fundamentais para a segurança das crianças nesse ambiente, sendo de simples execução e de baixo custo, podendo ser amplamente utilizadas ${ }^{(3)}$.
O estudo acima, em 1999, foi apresentado no encarte científico do Informe Criança, do Instituto da Criança do Hospital das Clínicas de São Paulo, destacando a importância da prevenção de acidentes em parques infantis ${ }^{(4)}$.

Assim, temos como finalidade, neste estudo, convidar à reflexão sobre a prevenção de acidentes na infância, em especial em parques infantis, assim como tecer recomendações gerais sobre prevenção de acidentes nesses locais.

\section{MORBIDADE E MORTALIDADE POR ACIDENTES EM PARQUES INFANTIS}

São comunicados anualmente, em departamentos de emergência nos Estados Unidos da América, cerca de 200.000 acidentes com pré-escolares e escolares, ocorridos em parques infantis. Estima-se que, a cada 2 minutos e meio, ocorra um acidente nesses locais, sendo que $35 \%$ destes são caracterizados como graves, e 3\% requerem hospitalização. A cada ano, aproximadamente 20 crianças morrem vítimas desse tipo de acidente, tendo como causa primária, em $75 \%$ dos casos, a queda do brinquedo associada a lesões cerebrais. Destacam-se, ainda, como conseqüências relacionadas a esse tipo de acidente: fraturas, lacerações, contusões, deslocamentos, amputações, esmagamentos e lesões internas ${ }^{(5)}$.

Dados semelhantes são relatados na literatura, pois $88 \%$ dos acidentes em parque infantil são causados por quedas, principalmente de equipamentos destinados ao desenvolvimento da agilidade, ou com obstáculos que favorecem desequilíbrio e quedas. As demais lesões são causadas por colisões, especialmente nos escorregadores e superfícies inapropriadas, ou ainda, mal conservadas com presença de lascas de madeira afiadas ou parafusos soltos $^{(6)}$.

Estima-se, ainda, que aproximadamente $40 \%$ dos acidentes nesse ambiente são resultados de uma supervisão inadequada ${ }^{(7)}$. É recomendável que a supervisão deva envolver o responsável pela criança, pelo parque e órgãos fiscalizadores.

Esses dados, apesar de norte-americanos, devido a sua abrangência, importância social e de saúde, devem servir como alerta para profissionais e autoridades, quanto à necessidade de intervenções e estudos sobre o tema em nosso país. 
RECOMENDAÇÕES SOBRE A PREVENÇÃO DE ACIDENTES EM PARQUES INFANTIS

A existência das normas da ABNT sobre segurança de brinquedos de parques infantis em nosso país é aspecto de extrema valia a ser destacado, enquanto diretriz que tem a possibilidade de conduzir a sociedade para a escolha correta desses equipamentos, desde que essas normas sejam aplicadas em todos os locais, sendo supervisionadas quanto ao seu cumprimento ${ }^{(2)}$.

Essas normas discorrem acerca do desempenho mecânico e de carga dos equipamentos, o tipo de acesso ao brinquedo, diretrizes de instalação de corrimões, barras e enchimento dos brinquedos, delimitação de espaços livres que possam provocar retenção de dedos, mãos, membros e cabeça, além de normas específicas para equipamentos estáticos, como aqueles destinados ao desenvolvimento de agilidade, escorregadores, balanços, equipamentos oscilantes, rotativos e conjugados. Acrescentam-se outras recomendações referentes à escolha e preparo do local de instalação, montagem e fixação do brinquedo, além do alerta para a necessidade de inspeção por organismo competente, sendo que, preferencialmente, deveria ser realizada duas vezes ao ano, ao término das temporadas de férias do inverno e verão ${ }^{(2)}$.

No entanto, de acordo com o cenário atual, para se conseguir um padrão de segurança faz-se necessário ir além. Em primeiro lugar, destacamos a importância da divulgação dessas normas, em segundo, que a responsabilidade da segurança deve envolver os fabricantes, as autoridades e as pessoas responsáveis pela instalação e manutenção desses equipamentos, incluindo-se os locais públicos e privados, como escolas, parques, prédios, clubes, dentre outros.

Consideramos relevante destacar resumidamente as recomendações para segurança de parques infantis baseadas no Plano de Ação Nacional para Prevenção de Acidentes em Playgrounds (EUA) do ano $2000^{(8)}$ :

1- Designar a idade apropriada para uso de cada

\section{REFERÊNCIAS BIBLIOGRÁFICAS}

1. Filocomo FRF, Harada MJCS, Silva CV, Pedreira MLG. Estudo dos acidentes na infância em um pronto socorro pediátrico. Rev Latino-am Enfermagem 2002; 10(1):41-7.

2 Associação Brasileira de Normas Técnicas - ABNT. Coletânea de normas de segurança de brinquedos de playground. Rio de Janeiro: ABNT; 1999. brinquedo do parque infantil. O brinquedo deve possuir identificações que determinem a qual faixa etária é destinado.

2- Instalar superfícies apropriadas em baixo e ao redor dos brinquedos. Essas superfícies devem absorver o impacto e não causar abrasão ou laceração da pele (borracha, produtos de cortiça e de madeira, areia e cascalho fino).

\section{3- Recomendar supervisão adequada para crianças} nos parques infantis. As crianças devem ser sempre supervisionadas, principalmente quando estão subindo, balançando e escorregando nos brinquedos.

\section{4- Realizar adequada manutenção dos parques} infantis. Sugere-se que haja três tipos de inspeções: a diária, a registrada (realizada a cada 1 a 3 meses) e a inspeção certificada que deverá ser realizada por profissional especializado a cada 8 a 12 meses. Os problemas observados devem ser comunicados imediatamente aos responsáveis pelo parque e, se necessário, ele deve ser interditado.

\section{CONSIDERAÇÕES FINAIS}

A prevenção de acidentes na infância, relacionados com brinquedos de parques infantis, constitui um problema de difícil operacionalização, pois não envolve somente o conhecimento sobre as normas de segurança. É preciso o engajamento dos profissionais que trabalham com crianças e a participação da sociedade como um todo, para exigir de seus legisladores ou representantes a adequada manutenção desse espaço de lazer e, ainda, obrigar fabricantes de brinquedos de parque infantil a garantirem a segurança de seus produtos.

Desse modo, esperamos contribuir com reflexões sobre o tema, encorajando os profissionais a participarem no processo de promoção da saúde, por meio da prevenção de acidentes com brinquedos em parques infantis. Lazer é coisa séria!

3. Sibert JR, Mott A, Rolf K, James R, Evans R, Kemp A, et al. Preventing injuries in public playgrounds throu partnership between health services and local authority: community intervention study. BMJ 1999 Jun; 318:1595.

4. Ramos SR. Prevenção de acidentes em parques infantis. Informe Criança 1999 agosto; (53):4.

5. Centers for Disease Control and Prevention. Playground safety [serial online] 2000 May [cited 2002 Mar 25]. Available from: URL:http://www.cdc.gov/safeusa/playgro/playgrou.htm 
6. Waltzman ML, Shannon M, Bowen AP, Bailey MC. Monkeybar injuries: Complications of play. Pediatrics 1999 May; 103(5):58.

7. Stone DH, Morrison A, Ohn TT. Developing injury surveillance in accident and emergency departments. Arch Dis Child 1998;78:108-10.

8. National Center for Injury Prevention and Control. National Program for Playground Safety [serial online] 2000 Jan [cited 2002 Apr 12]. Available from: URL: http://www.uni.edu/ playground/home.html 